\title{
ADSORÇÃO DE MATÉRIA ORGÂNICA EM CARVÃO ATIVADO GRANULAR NO PÓS TRATAMENTO DE LIXIVIADO DE ATERRO SANITÁRIO
}

\author{
Marcos Batista Mendes
}

Flávia kawahigashi

\section{Emília Kiyomi Kuroda}

RESUMO: Quando não tratado adequadamente, o lixiviado proveniente de aterros pode infiltrar e poluir mananciais e suas adjacências. Devido às características de lixiviado estabilizado, com elevadas concentrações de nitrogênio amoniacal, cloretos, metais, matéria orgânica recalcitrante, há grande dificuldade de tratamento dos mesmos, assim como um elevado custo operacional, para minimizar potenciais efeitos ao meio ambiente. Por consequência das propriedades físicas inerentes ao carvão ativado tais como grande área superficial, forma e estrutura de poros, alta capacidade adsortiva e reatividade da superfície à adsorção, o uso deste, têm recebido recentemente, considerável atenção quanto à capacidade de remover material orgânico e inorgânico de águas residuárias. Assim, este trabalho foi realizado com o objetivo de avaliar a aplicabilidade do sistema de adsorção/filtração em carvão ativado granular - CAG em relação à remoção de cor verdadeira, Demanda Química de Oxigênio- DQO e Carbono Orgânico Total - COT, como pós-tratamento de lixiviado tratado por stripping de amônia, seguido de lodos ativados e coagulação química-floculação-sedimentação. Para as condições utilizadas nos experimentos, pôde-se concluir que, a adsorção por CAG apresentou elevada eficiência com remoção de $100 \%$ para cor verdadeira, 82,5 \% para DQO com valor máximo residual de $86 \mathrm{mg} \cdot \mathrm{O}_{2} \cdot \mathrm{L}^{-1}$ e de $68 \%$ para COT com valor máximo residual de $39 \mathrm{mg} \cdot \mathrm{L}^{-1}$. 
Palavras chave: Gestão de lixiviados de aterro sanitário. Tratamento físico-químico. Matéria orgânica recalcitrante.

\section{INTRODUÇÃO}

Segundo levantamento do Ministério das Cidades pela Secretaria Nacional de Saneamento Ambiental (SNSA, 2010), a geração per capta média de resíduos domiciliares foi de $0,93 \mathrm{~kg} / \mathrm{hab} / \mathrm{dia}$. Relacionando esse dado com a estimativa da população no país para o mesmo ano, obtém-se o valor de 177 mil toneladas de resíduos/dia gerados.

A disposição de resíduos sólidos domésticos em países desenvolvidos é comumente realizada em aterros controlados ou sanitários. No entanto, essa prática vem sendo também empregada em países em desenvolvimento como o Brasil. Conforme Pesquisa Nacional de Saneamento Básico (PNSB, 2008), 50,2\% do volume de resíduos gerados são dispostos em aterros, sendo estes sanitários ou controlados. Em relação às regiões do Brasil, o Sul e Sudeste apresentam os maiores índices de destinação dos resíduos sólidos gerados em aterros, da ordem de $80 \%$ do total.

Uma vez dispostos, os resíduos passam pelo estágio de decomposição natural, composto de uma série de processos combinados, sendo eles físicos, químicos e biológicos, que perduram por décadas (KURNIAWAN, LO,CHAN 2006) e geram um resíduo líquido de mau odor, coloração intensa, elevada carga orgânica e poluidora, com características recalcitrantes e tóxicas denominado lixiviado / percolado de aterro sanitário, ou chorume.

As características quantitativas e qualitativas do lixiviado gerado dependem da idade do aterro e do tipo / composição química do resíduo e sofrem influência direta do ciclo hidrológico e das características do solo. A disposição adequada do lixiviado é, sem dúvida, um dos maiores desafios da gestão dos resíduos sólidos devido à possibilidade de contaminação / poluição dos mananciais subterrâneos e superficiais e requer a aplicação de técnicas para manejo dos resíduos e controle / tratamento do volume de lixiviado gerado. 
Entre os compostos presentes no lixiviado, destacam-se nitrogênio amoniacal, cloretos, metais, matéria orgânica, compostos organohalogenados, xenobióticos e compostos orgânicos recalcitrantes, tais como as substâncias húmicas. Em aterros antigos, o lixiviado estabilizado apresenta altas concentrações de nitrogênio amoniacal, baixa biodegradabilidade, representada pela razão entre a demanda bioquímica de oxigênio e a demanda química de oxigênio e elevada concentração de compostos de difícil degradação. Deve-se considerar ainda que após exaustão da capacidade de disposição de resíduos, a produção de lixiviado estende-se por cerca de 50 anos. A forma de tratamento mais comum desses lixiviados é de natureza biológica, porém sua eficiência é limitada para lixiviados estabilizados, que apresentam grande quantidade de compostos recalcitrantes, o que demanda a associação de processos complementares de tratamento para esse tipo de efluente. Nessa perspectiva, o emprego adicional de processos físicos e químicos tais como coagulação-floculação- sedimentação em lixiviados tratados previamente por stripping de amônia e lodos ativados tem-se mostrado relativamente eficiente no tratamento de lixiviados, removendo matéria orgânica biodegradável, cor verdadeira e parte da DQO (FELICl, 2010). No entanto, esse sistema de tratamento, ainda não é capaz de produzir lixiviado que atenda às legislações vigentes. Mais especificamente:

- O padrão de lançamento estabelecido pelo Anexo 7 da Resolução 70/2009 do CEMA relativo à DQO, limitado em $200 \mathrm{mg} \cdot \mathrm{L}^{-1}$, para efluentes provenientes de outras atividades quando não enquadradas às especificadas na referida resolução;

- O padrão de enquadramento de corpos de água doce clases2 e 3, estabelecido pela Resolução 357/2005 do CONAMA relativo à cor verdadeira, limitado em 75 $\mathrm{uH}$.

Assim, faz-se necessária a investigação de técnicas ou processos complementares para pós-tratamento desses lixiviados com destaque à adsorção em carvão ativado granular. 


\section{DESENVOLVIMENTO}

\subsection{Objetivos}

Assim o trabalho teve por objetivo avaliar a aplicabilidade do sistema de adsorção/filtração em carvão ativado granular (CAG). Tendo com principais parâmetros à remoção de cor verdadeira, demanda química de oxigênio (DQO) e carbono orgânico total (COT), nas seguintes etapas do tratamento: stripping de amônia, lodos ativados, seguido de coagulação química-floculação-sedimentação.

\subsection{Material e Métodos}

O trabalho foi desenvolvido no Laboratório de Hidráulica e Saneamento da Universidade Estadual de Londrina e foi dividido em 3 etapas:

- Tratamento preliminar por stripping de amônia seguido de tratamento biológico por lodos ativados em bateladas sequenciais e escala piloto;

- Pós-tratamento por coagulação-floculação-sedimentação utilizando cloreto férrico $\left(\mathrm{FeCl}_{3} \cdot 6 \mathrm{H}_{2} \mathrm{O}\right)$ como coagulante químico em reatores estáticos - Jarteste e escala de bancada;

- Pós-tratamento por adsorção em carvão ativado granular - CAG com escoamento contínuo e escala de bancada.

\subsubsection{Lixiviado Bruto}

O lixiviado bruto foi coletado no aterro de resíduos sólidos domiciliares da cidade de Rolândia - PR, em funcionamento há 8 anos, através de caminhão-tanque previamente lavado e preparado para não haver contaminação. Depois da coleta, o lixiviado foi armazenado em um reservatório de fibra de vidro com capacidade 
volumétrica de $5 \mathrm{~m}^{3}$, no Laboratório de Hidráulica e Saneamento da Universidade Estadual de Londrina - UEL.

\subsubsection{Caracterização físico-química do lixiviado}

Os lixiviados bruto e produzido, após cada etapa do tratamento, foram caracterizados segundo os parâmetros físico-químicos: pH, oxigênio dissolvido, temperatura, alcalinidade, cor verdadeira e aparente, série de sólidos, demanda bioquímica de oxigênio - DBO, demanda química de oxigênio - $D Q O$, nitrogênio Kjeldahl total - NKT, nitrogênio amoniacal, nitrito e metais, segundo métodos analíticos descritos em APHA, AWWA, WEF (2005). A análise de nitrato foi realizada de acordo com o método proposto por Cataldo (1975).

De forma geral, além da caracterização inicial e final de cada etapa do tratamento, os parâmetros relevantes das mesmas foram monitorados com frequência de: 7 dias para o tratamento preliminar por stripping de amônia, 1 dia para o tratamento biológico por lodos ativados na fase aeróbia, e 3 horas para a fase anóxica.

Já na fase do pós-tratamento por coagulação-floculação-sedimentação e por adsorção em carvão ativado granular - CAG foram avaliados os parâmetros: pH, cor aparente; cor verdadeira; DQO; COT e cloretos. A Tabela 1 apresenta os métodos utilizados para cada parâmetro analisado. 
Tabela 1 - Parâmetros e metodologias utilizadas

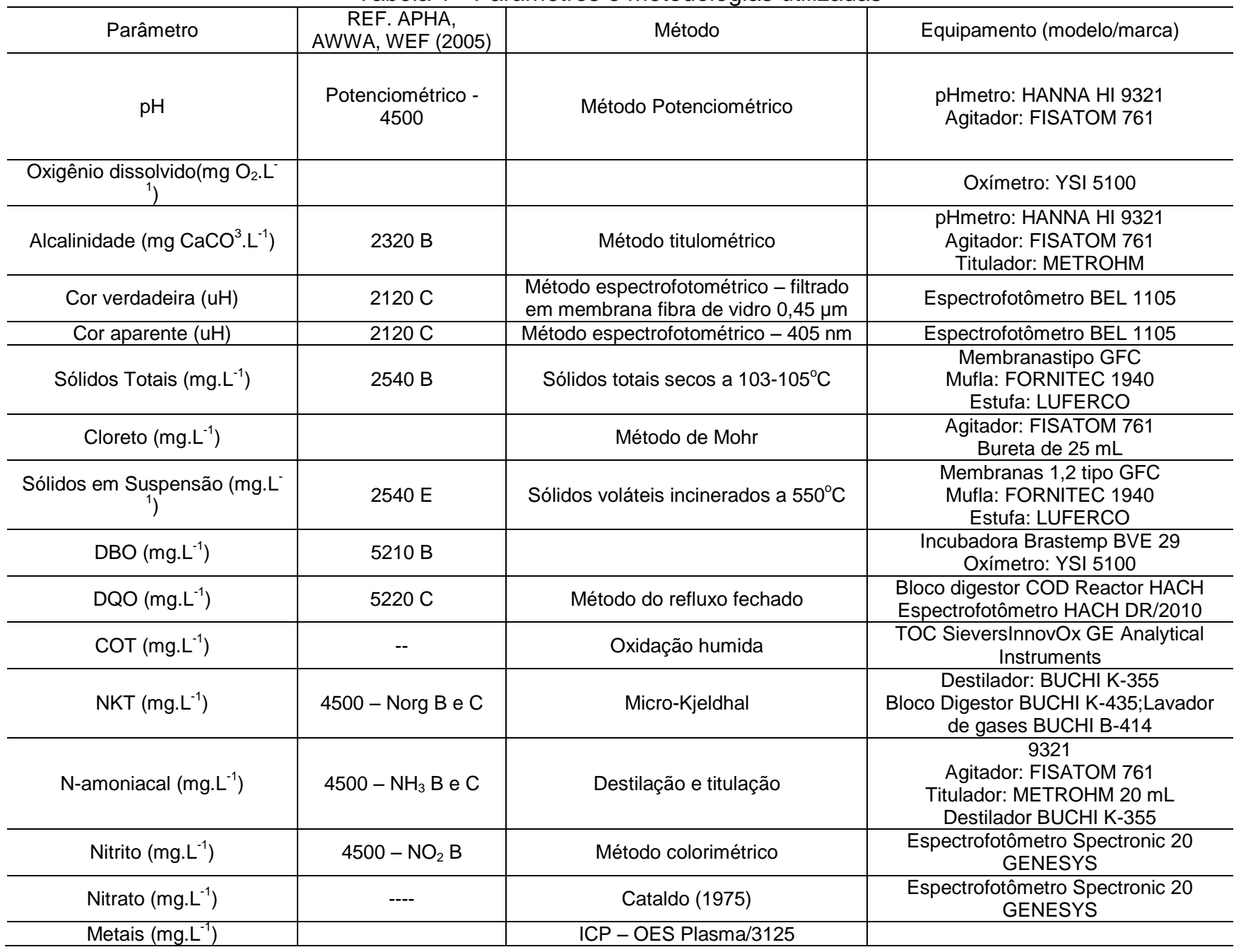

\subsubsection{Tratamento por Coagulação-Floculação-Sedimentação}

No tratamento por coagulação-floculação-sedimentação, os ensaios foram realizados em escala de bancada com a utilização do equipamento Jarteste (Nova Ética - 218/6LDBE), composto de 6 jarros de acrílico transparente de 2 L, tacômetro digital para visualização da rotação (até $600 \mathrm{rpm} \pm 2 \%$ ), o que confere gradiente de velocidade de até $1.200 \mathrm{~s}^{-1}$, dispositivo para aplicação de produtos químicos e coleta de água nos 6 jarros simultaneamente.

Considerando as condições operacionais da tabela 2. 
Tabela 2 - Parâmetros de controle operacionais para os ensaios de coagulação-floculaçãosedimentação em Jarteste

\begin{tabular}{c|c}
\hline Tempo médio de mistura rápida (Tmr) & $1 \mathrm{minuto}^{-1}$ \\
\hline Gradiente médio de velocidade de mistura rápida (Gmr) & $600 \mathrm{~s}^{-1}$ \\
\hline Tempo médio de floculação (Tfloc) & $20 \mathrm{minutos}^{-1}$ \\
\hline Gradiente médio de velocidade de floculação (Gfloc) & $20 \mathrm{~s}^{-1}$ \\
\hline Velocidade de sedimentação (VS) & $0,047{\mathrm{~cm} . \mathrm{min}^{-1}}^{2,5 \mathrm{~h}}$ \\
\hline Tempo de sedimentação & \\
\hline
\end{tabular}

Após o estabelecimento da condição de coagulação química de maior eficiência, foram realizados sucessivos ensaios, para esta condição obtendo-se assim volume de aproximadamente 500L de lixiviado, após tratamento por coagulação-floculaçãosedimentação, que foram homogeneizados e acondicionados em bombonas de capacidade volumétrica de $100 \mathrm{~L}$ para a realização do tratamento subsequente, por adsorção em carvão ativado granular - CAG.

\subsubsection{Pós tratamento por adsorção em carvão ativado granular CAG}

O tratamento por adsorção em carvão ativado granular - CAG foi realizado com escoamento contínuo em escala de bancada e com intuito de avaliar a eficiência da adsorção no CAG após sucessivas carreiras de adsorção/filtração

O esquema do sistema utilizado para o ensaio de adsorção em CAG com escoamento contínuo e escala de bancada apresentado na Figura 1e foi composto por:

- Um béquer com capacidade volumétrica de $5 \mathrm{~L}$ para o acondicionamento do lixiviado de estudo disposto sob um agitador magnético para manter a homogeneidade do mesmo durante o ensaio;

- Uma bomba peristáltica (Ismatec - ISM947C) de 12 canais para alimentação simultânea, contínua e independente dos 6 filtros por meio de mangueiras (Tygon, e de polipropileno com diâmetro interno - DI de 1,14 $\mathrm{mm}$ );

- Filtros de carvão ativado granular - FCAG cada qual contendo corpo em acrílico transparente de $18 \mathrm{~mm}$ de diâmetro, $40 \mathrm{~cm}$ de altura e areia 
aderida na parede interna de modo a evitar a formação de correntes preferenciais durante o processo de adsorção/filtração com altura de $9 \mathrm{~cm}$ de carvão ativado granular devidamente compactados.

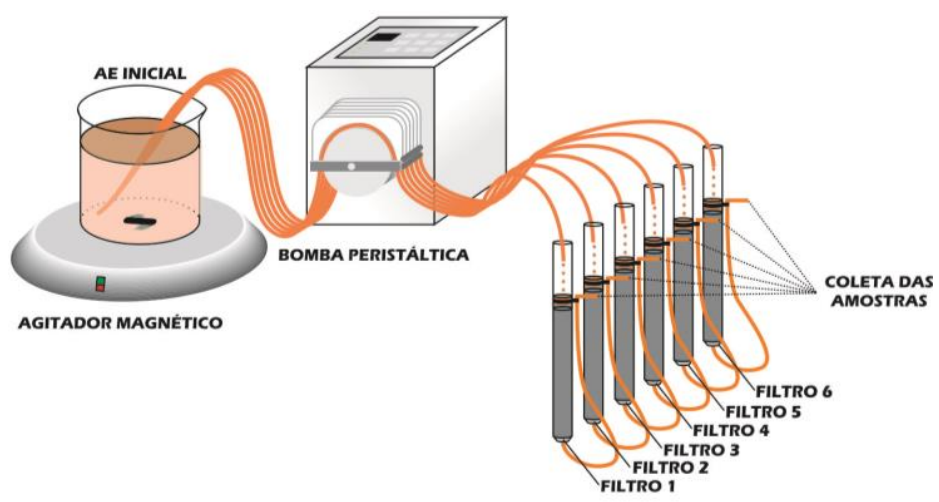

Figura 1 - Esquema do sistema de adsorção com escoamento contínuo e escala de bancada Fonte: Do Autor (2012)

O lixiviado sob homogeneização contínua foi conduzido através de mangueiras com o auxílio de uma bomba peristáltica alimentando assim os filtro de carvão ativado de forma simultânea, contínua e independente.

A bomba peristáltica foi previamente regulada para conduzir uma vazão constante de $0,79 \mathrm{~mL}$. $\mathrm{min}^{-1}$ para o topo de cada um dos FCAGs, resultando em um tempo de contato de 20 minutos. $O$ encerramento da carreira de filtração foi limitada à perda de carga máxima de $34 \mathrm{~cm}$.

Para avaliar a qualidade do lixiviado após adsorção, foram realizadas coletas a cada 6 horas ou em intervalos menores, e quando observada variação significativa de cor aparente e cor verdadeira ao longo do ensaio. Além disso, foram efetuadas medidas da perda de carga para monitoramento da colmatação do meio granular ao longo do tempo.

Para avaliar o impacto da carga de poluição/contaminação gerada pelo lançamento do volume total de lixiviados, após adsorção em corpos hídricos receptores, foram constituídas amostras compostas utilizando-se volumes fixos de todas as amostras coletadas para cada ensaio, ao longo do tempo, sendo assim, a cada 3 horas 
foram realizadas coletas pontuais para avaliar a remoção de cor aparente e medidas da perda de carga.

\subsection{Resultados e Discussão}

\subsubsection{Caracterização Físico-química do Lixiviado Bruto e Após Tratamento} Preliminar Por Stripping De Amônia Seguido De Tratamento Biológico Por Lodos Ativados

As características do lixiviado bruto remetem a um lixiviado já estabilizado, pois apresentou valores de $\mathrm{pH}$ de 9,1, DQO de $1819 \mathrm{mg} \cdot \mathrm{L}^{-1}$, DBO de $55 \mathrm{mg} \cdot \mathrm{L}^{-1}$, relação $\mathrm{DBO} / \mathrm{DQO}$ de 0,03 , cor verdadeira de $4180 \mathrm{uH}$ e nitrogênio amoniacal de $859 \mathrm{mg}$ $\mathrm{N}-\mathrm{NH}_{3} \cdot \mathrm{L}^{-1}$. A Tabela 2 e Tabela 3 apresentam os resultados da caracterização físicoquímica do lixiviado bruto e após tratamento preliminar por Stripping de amônia seguido de Tratamento Biológico por Lodos Ativados.

Tabela 2 - Caracterização físico-química do lixiviado bruto

\begin{tabular}{c|c|c}
\hline Parâmetro & & Parâmetro \\
\hline $\mathrm{pH}$ & -- & 9,1 \\
\hline Alcalinidade & $\mathrm{mg} \mathrm{CaCO}_{3} \cdot \mathrm{L}^{-1}$ & 4238 \\
\hline Cor verdadeira & $\mathrm{uH}$ & 4180 \\
\hline $\mathrm{NKT}$ & $\mathrm{mg} \mathrm{N}-\mathrm{NH}_{3} \cdot \mathrm{L}^{-1}$ & 997 \\
\hline $\mathrm{m}$-amoniacal & $\mathrm{mg} \mathrm{N}-\mathrm{NH}_{3} \cdot \mathrm{L}^{-1}$ & 859 \\
\hline Nitrito & $\mathrm{mg} \mathrm{N}-\mathrm{m} \mathrm{O}_{2} \cdot \mathrm{L}^{-1}$ & 0,1 \\
\hline Nitrato & $\mathrm{mg} \mathrm{O} \mathrm{mO}_{2} \mathrm{~L}^{-1}$ & 0 \\
\hline DBO & $\mathrm{mg} \mathrm{O}_{2} \cdot \mathrm{L}^{-1}$ & 55 \\
\hline DQO & & 1819 \\
\hline
\end{tabular}

Pode-se observar que após o tratamento preliminar por stripping de amônia seguido de tratamento biológico por lodos ativados as remoções de cor aparente e verdadeira foram da ordem de 9 e 19\% o que correspondem aos valores de 5419 e 3386 $\mathrm{uH}$, respectivamente. Com relação à $\mathrm{DQO}$, este não apresentou remoção durante a referida fase.

Tabela 3- Caracterização físico-química dos lixiviados de estudo e após tratamento preliminar por stripping de amônia seguido de tratamento biológico por lodos ativados 


\begin{tabular}{|c|c|c|c|c|c|c|c|}
\hline Parâmetro & Unidade & Inicial & Stripping & $\begin{array}{c}\text { \% Remoção } \\
\text { após } \\
\text { Stripping }\end{array}$ & Aeróbio & Anóxico & $\begin{array}{c}\text { \% Remoção } \\
\text { após } \\
\text { Tratamento } \\
\text { Biológico }\end{array}$ \\
\hline $\mathrm{pH}$ & - & 9,1 & 8,4 & - & 6,4 & 9,7 & - \\
\hline Alcalinidade & $\begin{array}{c}\mathrm{mg} \\
\mathrm{CaCO}_{3} \mathrm{~L}^{-1}\end{array}$ & 4238 & 2259 & 47 & 238 & 1401 & 67 \\
\hline $\begin{array}{l}\text { Oxigênio } \\
\text { dissolvido }\end{array}$ & $\mathrm{mg} \mathrm{O}_{2} \cdot \mathrm{L}^{-1}$ & \multicolumn{2}{|c|}{0,5 a 0,9} & - & 8,4 & 0,3 & - \\
\hline Cor aparente & $\mathrm{uH}$ & 5985 & - & - & - & 5419 & 9 \\
\hline Cor verdadeira & $\mathrm{uH}$ & 4180 & - & - & - & 3386 & 19 \\
\hline NKT & $\mathrm{mg} \mathrm{N}-\mathrm{NH}_{3} \cdot \mathrm{L}^{-}$ & 997 & 438 & 56 & 85 & - & - \\
\hline $\mathrm{N}$-amoniacal & $\mathrm{mg} \mathrm{N}_{1} \mathrm{NH}_{3} \mathrm{~L}^{-}$ & 859 & 325 & 62 & 13 & 12 & 98 \\
\hline Amônia & $\mathrm{mg} \cdot \mathrm{L}^{-1}$ & 253 & 44 & 82 & 25,4 & 0 & 100 \\
\hline Nitrito & $\mathrm{mg} \mathrm{N}_{1} \mathrm{NO}_{2} \cdot \mathrm{L}^{-}$ & 0,1 & 65,6 & - & 370,3 & 0,2 & - \\
\hline Nitrato & $\mathrm{mg} \mathrm{N}-\mathrm{NO}_{3} \cdot \mathrm{L}^{-}$ & 0 & 9,8 & - & 40,9 & 2 & - \\
\hline DBO & $\mathrm{mg} \mathrm{O}_{2} \cdot \mathrm{L}^{-1}$ & 55 & 45 & 18 & 57 & - & - \\
\hline DQO & $\mathrm{mg} \mathrm{O}_{2} \cdot \mathrm{L}^{-1}$ & 1819 & 1816 & 0 & 1753 & 2022 & - \\
\hline
\end{tabular}

\subsubsection{Tratamento por Coagulação-floculação-sedimentação}

O Gráfico 1 ilustra os valores de cor verdadeira e residual referentes aos 22 ensaios realizados pelo pós-tratamento por coagulação-floculação-sedimentação. Podese observar que de maneira geral, as porcentagens de remoção de cor verdadeira variaram de 67 - $99 \%$ de remoção. 

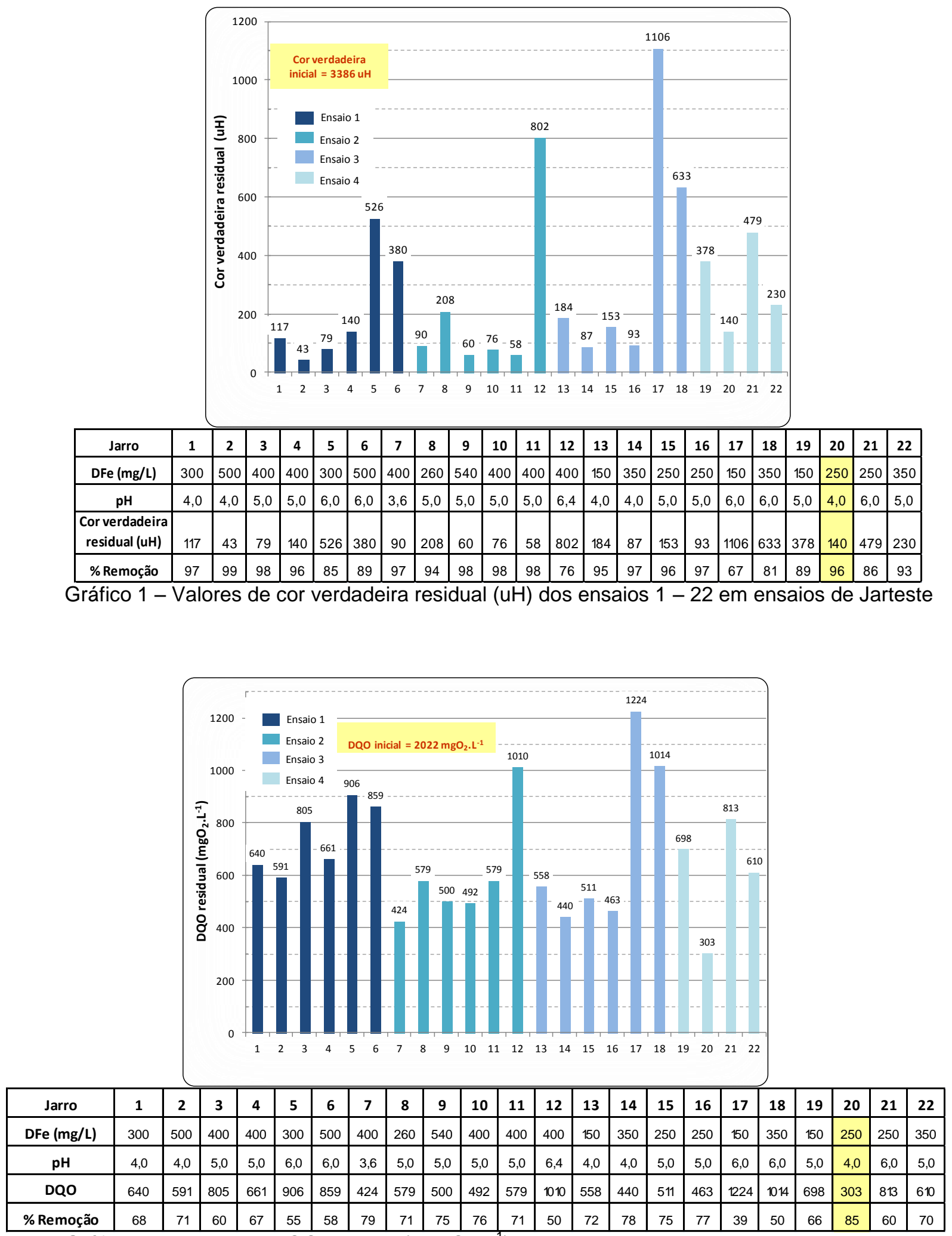

Gráfico 2 - Valores de DQO residual $\left(\mathrm{mg} \cdot \mathrm{O}_{2} \cdot \mathrm{L}^{-1}\right)$ dos ensaios 1 - 22 em ensaios de Jarteste 
Já o Gráfico 2 mostra os valores de DQO residual referentes aos 22 ensaios realizados pelo tratamento por coagulação-floculação-sedimentação. Pode-se observar que as porcentagens de remoção variaram de $39-85 \%$.

Considerando a aplicação deste tratamento em escala real, a quantidade de produtos químicos utilizados, e o custo necessário para sua aquisição, a seleção da melhor condição de coagulação química foi realizada, considerando a relação custo eficiência.

Analisando desta forma os resultados dos residuais de cor verdadeira e DQO, a condição selecionada foi a do ensaio 20, em que foram aplicado $250 \mathrm{mg}$ de $\mathrm{Fe}^{3+} \mathrm{em} \mathrm{pH}$ 4, correspondendo à remoção de 96 e 85 \% respectivamente de cor verdadeira e DQO.

n.a.: não analisado

Gráfico 3 apresenta os valores de cor aparente e verdadeira, DQO, carbono orgânico total - COT cloretos do lixiviado bruto e dos lixiviado produzido, após os tratamentos realizados com suas respectivas \% de remoção, sendo esta, calculada em função da etapa anterior de cada tratamento. 


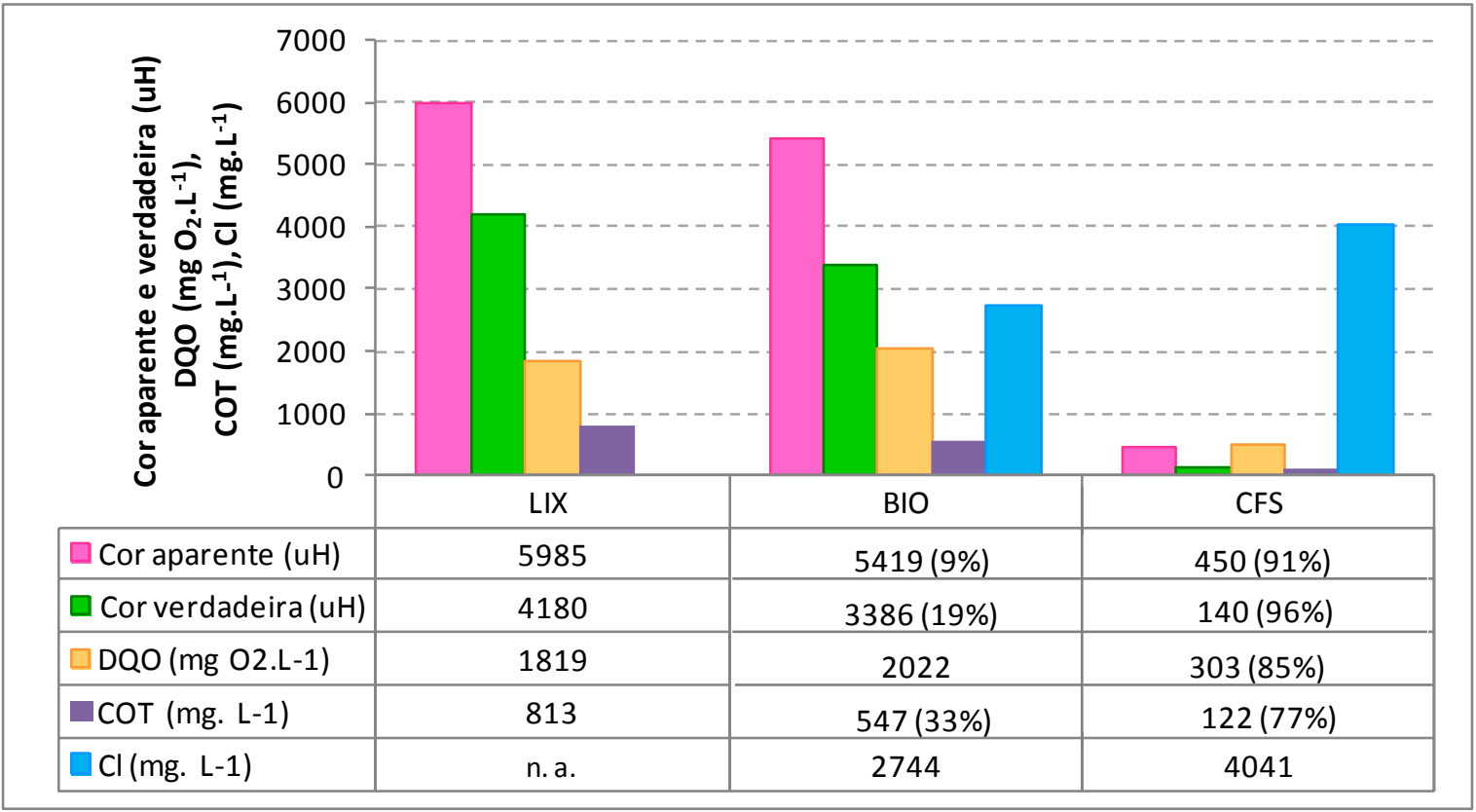

n.a.: não analisado

Gráfico 3 - Valores de cor aparente e verdadeira, DQO e cloretos do lixiviado bruto e após os tratamentos realizados e suas respectivas \% de remoção

Pelos resultados obtidos com 0 tratamento por coagulação-floculaçãosedimentação, o lixiviado produzido apresentou valores de cor verdadeira e DQO superiores aos limites estabelecidos para condições de enquadramento para águas doces classe 2 e 3 da Resolução 357/2005 do CONAMA, com valor de 75 uH para cor verdadeira.

Já para o limite do parâmetro DQO, padrão este de lançamento estipulado pela Resolução 70/2009 do CEMA, limita à DQO em $200 \mathrm{mg}^{-\mathrm{L}^{-1}}$ para efluentes provenientes de outras atividades, quando não enquadradas às especificadas na referida resolução. Assim, o lançamento direto deste lixiviado poderá prejudicar a qualidade dos corpos hídricos, o que comprova a necessidade do tratamento complementar, como é proposto neste trabalho. 


\subsubsection{Pós-tratamento por adsorção em carvão ativado granular - CAG}

O Gráfico 4 representa os valores de cor residual, aparente e verdadeira, e as respectivas perda de carga em função do tempo, do ensaio de adsorção/filtração em carvão ativado granular.

O ensaio teve duração de $138 \mathrm{~h}$, segundo critério de encerramento de perda de carga máxima, fixada em $34 \mathrm{~cm}$.

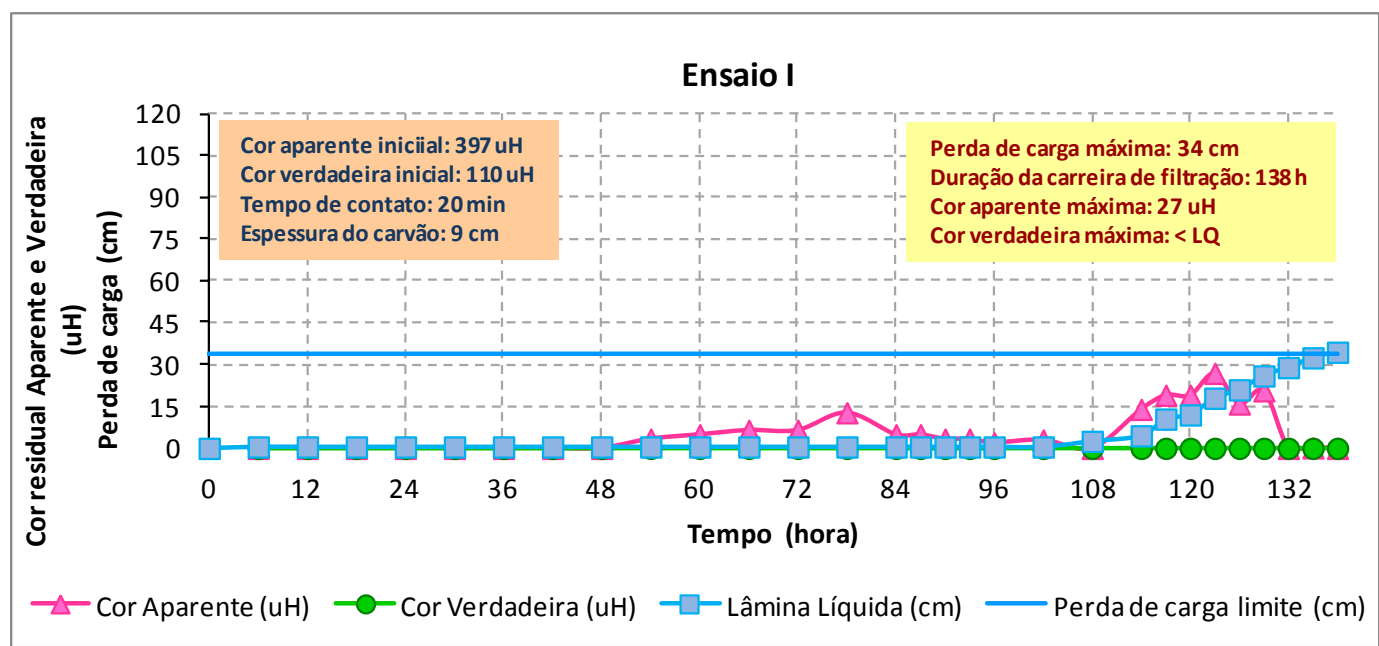

Gráfico 4 - Valores de cor residual aparente e verdadeira e perda de carga em função do tempo - Ensaio I

No ensaio foi observado a ocorrência de picos de cor aparente com valor máximo da ordem de 28 uH durante as 24 horas finais do ensaio de adsorção/filtração, no entanto manteve se com elevada eficiência de remoção de cor verdadeira neste período. Este fato pode ser justificado pelo desprendimento de flocos adsorvidos durante o próprio ensaio, uma vez que o material granular, ainda não havia sido utilizado.

Como esperado, pode se observar que a qualidade do lixiviado em relação aos valores residuais de cor aparente e verdadeira, diminuíram ao longo do ensaio indicando a perda de eficiência do adsorvente.

Este comportamento evidencia a diminuição da capacidade de adsorção do CAG, resultando em duração total de adsorção/filtração de 134 h. Por outro lado, o 
FCAG foi ainda relativamente eficiente na remoção de cor verdadeira seria possível, lavar o filtro e recomeçar o tratamento utilizando o mesmo meio granular.

Durante todo o tempo de operação, considerando o valor limite de cor verdadeira de 75 uH estabelecido pela Resolução 357/2005 do CONAMA para corpos hídricos de classe 2 e 3 . Desta forma, pode-se constatar que o lixiviado produzido pelo póstratamento de adsorção em carvão ativado granular, atendeu sistematicamente a esse parâmetro.

Para avaliar o impacto da carga de poluição/contaminação gerada pelo lançamento do volume total de lixiviados após adsorção, em corpos hídricos receptores, foram constituídas amostras compostas utilizando-se volumes fixos de todas as amostras coletadas, no ensaio ao longo do tempo. Os valores residuais de cor aparente e verdadeira, DQO, COT e cloretos bem como suas percentagens de remoção calculadas em função da etapa anterior estão apresentados no n.a.: não analisado

Gráfico 8.

A Figura 2 mostra a foto do lixiviado bruto- LIX, o lixiviado produzido após o tratamento biológico - BIO e após o pós-tratamento por coagulação-floculaçãosedimentação - CFS e das amostras compostas dos lixiviados produzidos no ensaio I codificado por CAG I

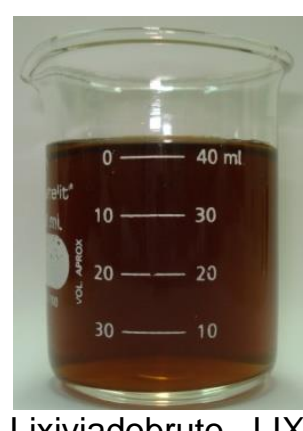

Lixiviadobruto- LIX

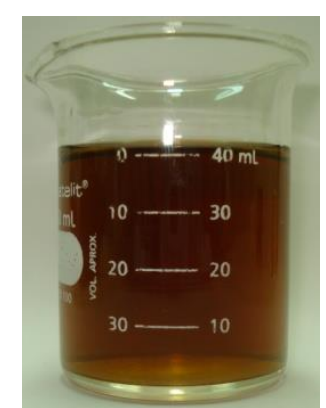

Lixiviado após tratamento biológico $\mathrm{BIO}$

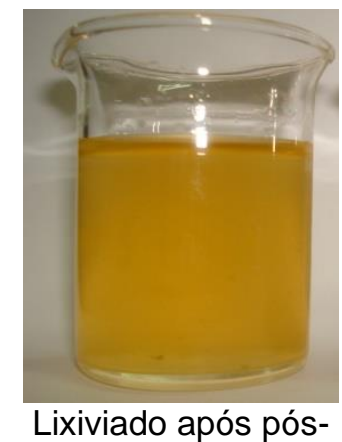
tratamento por coagulação-floculaçãosedimentação - CFS

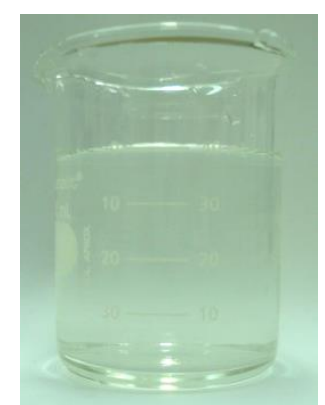

Amostra composta dos lixiviados produzidos no ensaio I - CAG I

Figura 2 - Foto das amostras compostas dos lixiviados produzidos no ensaio de adsorção/filtração Fonte: Do Autor (2012) 
Pelo pós-tratamento de adsorção em CAG pode-se observar que as remoções de cor aparente e verdadeira durante o ensaio apresentou elevada eficiência, $100 \%$ de remoção permanecendo sempre abaixo do limite de quantificação, ou seja, sistematicamente inferior ao limite de $75 \mathrm{uH}$, que é estabelecido na Resolução 357/2005 do CONAMA,para as condições de enquadramento para águas doces classes 2 e 3 .

Em relação à DQO, foi observada remoção de $82,5 \%$, resultando em valor de

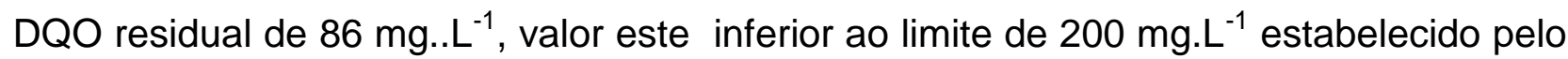
padrão de lançamento da Resolução №. 0070/2009 - CEMA·, para efluentes provenientes de outras atividades, quando não enquadradas às especificadas na referida resolução.

Embora nenhuma resolução consultada, faça menção sobre os valores permitidos de carbono orgânico total - COT, tanto para enquadramento, como para padrão de lançamento, durante os tratamentos empregados foram verificados remoções de $68 \%$ com valor residuais de $39 \mathrm{mg} \cdot \mathrm{L}^{-1}$.

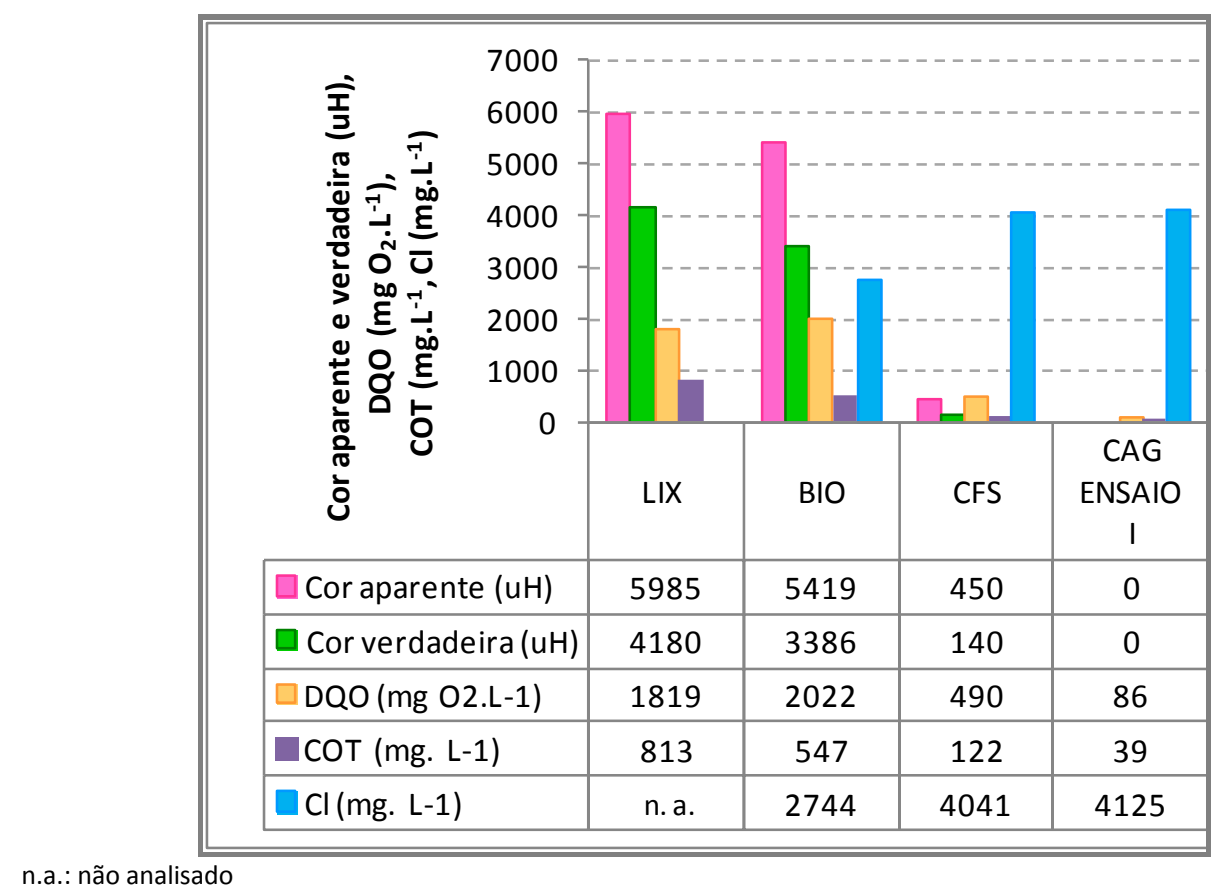

Gráfico 5 - Valores de cor aparente e verdadeira, DQO, COT e cloretos do lixiviado bruto e após os tratamentos realizados e suas respectivas \% de remoção 


\section{CONCLUSÃO}

Para o lixiviado de estudo proveniente do aterro sanitário da cidade de Rolândia - PR foi possível concluir que:

- Em relação ao pós-tratamento por coagulação-floculação-sedimentação utilizando cloreto férrico como coagulante químico em reatores estáticos - Jarteste e escala de bancada, a melhor condição de coagulação química correspondeu à aplicação de $250 \mathrm{mg} \mathrm{Fe}{ }^{3+}$ em pH 4,0 obtendo-se remoções de 96\% de cor verdadeira e 85 $\%$ de DQO, com valores residuais de $140 \mathrm{uH}$ e $303 \mathrm{mg} \cdot \mathrm{L}^{-1}$, respectivamente;

- No pós-tratamento por adsorção com escoamento contínuo e escala de bancada , utilizando-se o carvão ativado granular - CAG pode-se constatar a perda de eficiência ao longo do tempo durante o ensaio de adsorção/filtração, atingindo a perda de carga limite com $138 \mathrm{~h}$ de operação.

- O lixiviado produzido por adsorção no CAG apresentou ao longo do ensaio elevada eficiência, com remoção de 100 \% para cor verdadeira, 82,5 \% para DQO com valor máximo residual de $86 \mathrm{mg} \cdot \mathrm{O}_{2} \cdot \mathrm{L}^{-1}$ e de $68 \%$ para COT com valor máximo residual de $39 \mathrm{mg} \cdot \mathrm{L}^{-1}$.

\section{REFERÊNCIAS}

INSTITUTO BRASILEIRO DE GEOGRAFIA E ESTATístICA (IBGE). Pesquisa Nacional de Saneamento Básico. Apresentada em 2008. Disponível em: www.ibge.gov.br.

KURNIAWAN, T.A.; LO, W.; CHAN, G. Physico-chemical treatments for removal of recalcitrant contaminants from landfill leachate, J. Hazard. Mater. 129 (2006) 80100.

FELICI, E. M. Coagulação-floculação-sedimentação como pós-tratamento de efluente de sistema biológico em batelada aplicado a lixiviado de aterro de 
resíduos sólidos urbanos. Dissertação (Mestrado em Engenharia de Edificações e Saneamento) -Universidade Estadual de Londrina, Centro de Tecnologia e Urbanismo. Londrina - PR, 2010.

BRASIL, Ministério do Meio Ambiente. Conselho Nacional de Meio Ambiente. Resolução no 357, 17 de março de 2005. Dispõe sobre a classificação dos corpos de água e diretrizes ambientais para o seu enquadramento, bem como estabelece as condições e padrões de lançamento de efluentes, e dá outras providências. Brasília, 2005.

PARANÁ, Conselho Nacional do Meio Ambiente. Resolução 0070/2009 - CEMA. Dispõe sobre o licenciamento ambiental, estabelece condições e critérios e dá outras providências, para Empreendimentos Industriais. Curitiba, 2009.

APHA, AWWA, WEF (2005). Standard Methods for the Examination of Water and Wastewater. American Public Health Association (APHA), American Water Works Association (AWWA) e Water Environment Federation (WEF) / $21^{\underline{a}}$ edição.

CATALDO, D.A.; HAROON, M.; SCHRADER, L.E.; YOUNGS, V.L. Rapid Colorimetric Determination of Nitrate in Plant Tissue by Nitration of Salicylic Acid. Communications in Soil Science and Plant Analysis, v.6, p.71-80, 1975.

KAWAHIGASHI, F. Pós-tratamento de Lixiviado de Aterro sanitário por Adsorção em Carvão Ativado Granular com Avaliação Ecotoxicológica. Dissertação apresentada ao Programa de Pós-Graduação em Engenharia de Edificações e Saneamento. Universidade Estadual de Londrina. Londrina, 2012. 